\title{
Support needs of patients with obesity in primary care: a practice-list survey
}

\author{
Elizabeth H. Evans ${ }^{1 * \dagger}$, Kirby Sainsbury ${ }^{1 \dagger}$, Dominika Kwasnicka ${ }^{2}$, Alex Bolster ${ }^{1}$, Vera Araujo-Soares ${ }^{1}$ \\ and Falko F. Sniehotta'
}

\begin{abstract}
Background: UK guidelines recommend that patients with obesity in primary care receive opportunistic weight loss advice from health care professionals, but there is a lack of research into the characteristics and existing weight management practices of these patients. The aim of this study was to characterise primary care patients with obesity in England, to inform the screening, support, and referral options appropriate to this group.

Methods: We surveyed 1309 patients registered at 15 GP practices in North East England, aged $\geq 18$ years and with objectively recorded obesity $\left(\mathrm{BMI} \geq 30 \mathrm{~kg} / \mathrm{m}^{2}\right)$. Study participants reported their weight history, health status, past and current weight loss activities, motivating factors, weight loss strategies used, professional support received, and perceived barriers to weight loss.

Results: $62 \%$ of participants were actively trying to lose weight, and a further $15 \%$ had attempted and discontinued weight loss in the last 12 months. Only 20\% of the sample had sought GP support for weight loss in the last 12 months; instead, most efforts to lose weight were self-guided and did not use evidence-based strategies. Those who sought GP weight loss support were likely to use it and find it motivating. Participants had attempted weight loss on multiple previous occasions and overall felt less confident and successful at maintaining weight loss than losing it. Participants at greatest clinical risk (higher BMl and more health conditions) reported particularly low confidence and multiple barriers to weight loss, but were nevertheless highly motivated to lose weight and keep it off.

Conclusions: We identified the need for informational, structural, and weight loss maintenance-specific support for GP patients with objectively-recorded obesity. Study participants were motivated to lose weight and keep it off, but lacked the confidence and understanding of effective strategies required to do this. GP weight loss support was acceptable and useful but underutilised, indicating that screening and brief referral interventions to structured programmes may augment patients' current weight management activities and meet key support needs whilst optimising limited primary care resources.
\end{abstract}

Keywords: Obesity, Overweight, Primary health care

\section{Background}

A quarter of UK adults have a body weight that places them in the range for obesity $\left(\geq 30 \mathrm{~kg} / \mathrm{m}^{2}\right)[1]$, and consequently at elevated risk for weight-related morbidity [2] and mortality [3]. Sustained weight loss of $5-10 \%$ is effective in reducing medical risk for these individuals [4]. UK guidelines therefore recommend that primary care staff screen for obesity in the office setting, and

\footnotetext{
* Correspondence: elizabeth.evans@newcastle.ac.uk

${ }^{\dagger}$ Equal contributors

${ }^{1}$ Institute of Health \& Society, Newcastle University, Newcastle upon Tyne NE2 4AX, UK

Full list of author information is available at the end of the article
}

opportunistically encourage affected individuals to lose weight by offering advice and signposting to available lifestyle management services [5-7]. Despite recent evidence that brief referral interventions initiated in GP settings are effective [8,9], concerns about the acceptability of providing weight loss advice [10] have meant that advice and referral are seldom done in practice [11].

Little is known about the potential recipients of weight loss advice: the characteristics, needs and weight management experiences of patients classified as obese presenting in primary care. Most previous research into weight loss attempts in the UK has focused upon the 
general population, notably via the Health Survey for England (HSE) [12, 13]. HSE participants with a BMI $\geq 30 \mathrm{~kg} / \mathrm{m}^{2}$ were more likely to report an ongoing weight loss attempt than those with a BMI in the healthy range (76 vs. $30 \%$ ), and this likelihood was higher still if weight loss had been advised by a health care professional [14]. It is not known whether weight loss attempts in the general practice population with obesity are equally prevalent. Overall, information is needed about the broader weight-related context of patients with obesity in primary care, particularly given the higher intensity of primary healthcare usage in this group [15]. Individuals with obesity are frequently subject to stigmatisation and discrimination $[16,17]$, and it is vital that weight management offered in primary care is non-judgemental, supportive and both informed by and sensitive to patients' previous experiences.

In the current study, we therefore examined the weight management activities, experiences, needs and attitudes of individuals with obesity in a primary care population, using a postal survey distributed via GP surgeries. We asked participants about their weight history, the importance they placed on weight loss and weight loss maintenance, confidence, past success, motivating factors, use of weight loss strategies, the impact of health conditions on weight control, and other perceived barriers. The aim of this study was to characterise primary care patients with obesity in England, with a view to informing recommendations for the screening, support, and referral options appropriate to this previously undescribed group.

\section{Method}

\section{Participants and recruitment procedure}

Practice administrative staff identified potential participants at 15 General Practices in North East England (Northumberland and Tyne \& Wear) by screening medical record databases in July and August 2015. Patients were eligible if they were aged $\geq 18$ years and had a read code for BMI $\geq 30 \mathrm{~kg} / \mathrm{m}^{2}$ or for obesity (any type of obesity coded within EMIS/SystmOne) recorded in their notes within the past 12 months. The practice sent a study pack to eligible patients consisting of a personalised letter from the practice, an information sheet and consent form, the study survey, and a postage-paid return envelope addressed to the University. As a gesture of thanks, participants were invited to enter a prize draw to win one of three $£ 100$ shopping vouchers by completing an entry form and returning it with the survey in the envelope. The North East and Cumbria Clinical Research Network facilitated recruitment of practices to the study and survey distribution. Ethics approval was obtained on 6 February 2014 from the East Midlands-
Derby National Research Ethics Service (REC: 14/EM/ 0069).

\section{Materials}

The survey was designed to obtain the following information from participants:

1. Demographic details, self-rated health (rated from 1 to 5 , excellent to poor), and details of current health conditions;

2. Current height and weight, highest and lowest adult weights (excluding pregnancy), number of previous weight loss attempts (lifetime), whether a weight loss attempt was ongoing and, if not, the length of time since last trying to lose weight;

3. In reference to participants' previous weight management efforts overall, confidence to lose weight and maintain weight loss, the perceived importance of weight loss and weight loss maintenance, and previous weight loss and weight loss maintenance success (all rated from 1 to 6 , very low to very high);

4. Motivating factors for weight loss in participants' most recent weight management efforts (participants selected from a list of 13 common motivating factors and/or specified any other factor(s));

5. Use of weight loss methods within the last 12 months (participants selected from a list of 21 common weight loss strategies and/or specified 'any other strategy/ies), use and source of professional weight loss support within this timeframe, usual frequency of self-weighing, and current levels of physical activity (vigorous, moderate and walking), using the International Physical Activity Questionnaire - Short Form (IPAQ-SF) [18];

6. Perceived barriers to weight loss in participants' most recent weight management efforts (participants selected from a list of 9 common barriers to weight loss and/or specified any other barrier(s)).

7. Any other information participants wished to provide, in a free-text box.

The complete set of questions is provided as an additional file (Additional file 1).

\section{Data analysis}

Data were manually entered and analysed using SPSS version 21 [19]; a subset were second-entered to check for accuracy. Ratio and interval-level data were examined for the assumptions of parametric analysis through visual inspection of histograms and Kolmogorov-Smirnov calculations. BMI was computed from self-reported height and weight data using the following formula: $\mathrm{BMI}=$ weight $(\mathrm{kg}) /$ height $^{2}(\mathrm{~m})$. The $p$ value threshold was set a priori at $p<0.001$ to avoid type 1 errors as a result of multiple 
comparisons. Missing data were dealt with using pairwise deletion as appropriate, and non-plausible height and weight data were excluded from analyses. Pearson's correlation coefficient was used to express associations between variables, and between-group differences were examined using independent-samples $t$-tests and Pearson chi-squared tests. Free-text data provided in the comments box were analysed using a content-analytic approach [20], in which a coding frame was developed to describe the thematic content and codes assigned to comments by two independent coders.

\section{Results}

\section{Sample characteristics}

Participants returned 1309 completed surveys out of 5800 sent (response rate $=23 \%$ ). The sample had a mean age of $59 \pm 14$ years (range $=18-97$ ) and $54 \%$ were women. The majority (90\%) self-identified as white British, whilst the remainder self-identified as belonging to other categories (e.g., White European: 1\%; mixed race: $1 \%$ ) or preferred not to say $(8 \%)$. Roughly a third of the sample was married or cohabitating $(61 \%$ and $7 \%$ respectively); the remainder was single (11\%), separated or divorced (10\%), or widowed (8\%). Just over half the sample had completed education beyond sixth form (degree: $18 \%$; vocational: $35 \%)$; the other half had completed A-levels (6\%); GCSEs (14\%); other (1\%); or had education below high school level (20\%; prefer not to say/ missing: 6\%).

\section{Health status and health conditions}

Most participants (83\%) reported at least one current health condition, including hypertension (45\%), chronic pain (42\%), mobility problems (34\%), diabetes (27\%), and depression and/or anxiety (25\%). Respondents who reported at least one health condition were older $(r=0.29$, $p<0.001)$ and had a significantly higher BMI $(r=0.13, p$ $<0.001)$ than those without. Participants described their overall health as poor (12\%), fair (35\%), good (38\%), very good (13\%), or excellent (1\%). Participants with higher BMIs reported poorer health $(r=-0.17, p<0.001)$; selfrated health did not vary with age $(r=-0.05, p=0.11)$ or gender $(r=0.01, p=0.85)$.

\section{Weight and weight loss history}

Table 1 summarises participants' weight, weight history, and BMI by gender. According to current self-reported weight, $83 \%$ of the sample fell into the obese category (BMI $\geq 30 \mathrm{~kg} / \mathrm{m}^{2}$ ), whilst $17 \%$ was classified as overweight (BMI 25-29.9 $\mathrm{kg} / \mathrm{m}^{2}$ ). A BMI in the healthy range was reported by 7 participants $(0.5 \%)$. Women had significantly higher current $\left(t_{(1243)}=-7.5, p<0.001\right)$ and lifetime highest $\left(t_{(1238)}=-7.5, p<0.001\right)$ BMIs compared to men, but lower lifetime lowest BMIs than men
Table 1 Current and lifetime highest/lowest weights and corresponding BMls by gender

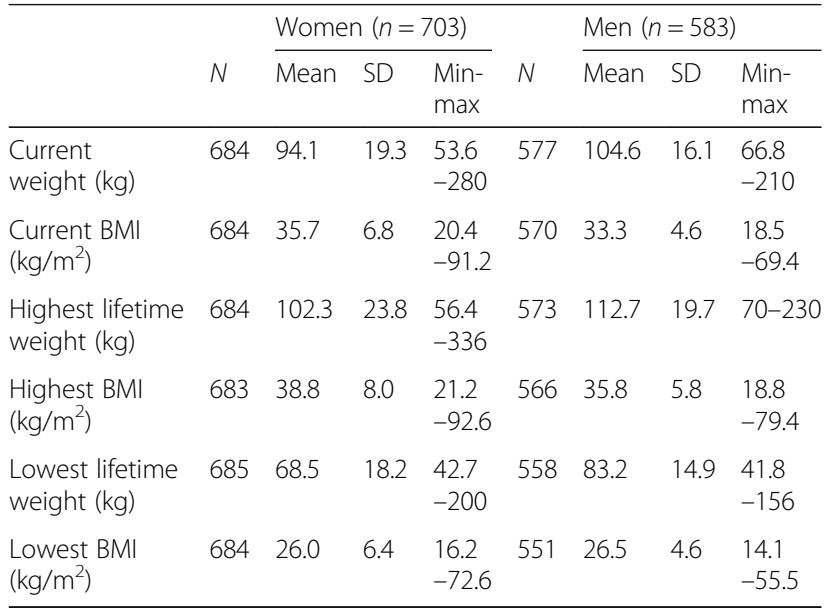

Gender data missing for 23 participants. Highest lifetime weight

excludes pregnancy

$\left(t_{(1226)}=1.7, p<0.001\right)$. Around a third $(31 \%)$ of the sample reported that their weight had stayed the same $(+/-2 \mathrm{~kg})$ over the past 12 months; equivalent numbers reported weight loss $(16 \%)$ and weight gain (16\%), and $36 \%$ said their weight had fluctuated during this time.

Almost two thirds (62\%) of the sample reported that they were currently trying to lose weight. Among these participants, this current attempt had lasted anywhere from 1 day to more than 50 years (median $=1$ year; IQR $=17-104$ weeks). Only $7 \%$ of participants reported having never attempted weight loss, while for the remainder, their most recent attempt was within the last 3 months (3.2\%), within the last 6 months $(2.7 \%)$, within the last 12 months $(9.1 \%)$, or more than 12 months ago (15.1\%). A greater proportion of the women (70\%) were currently attempting weight loss than men $\left(53 \% ; \chi_{(2)}^{2}=45.7, p<\right.$ 0.001 ); women also reported a greater number of weight loss attempts in their lifetimes (16 \pm 34 attempts) than men $\left(9 \pm 21\right.$ attempts; $\left.t_{(1004)}=-3.9, p<0.001\right)$. Participants currently trying to lose weight were significantly younger $(57.6 \pm 14.8$ years $)$ than those who were not $(61.1 \pm$ 13.4 years; $\left.t_{(1243)}=4.1, p<0.001\right)$.

\section{Weight loss: Importance, perceived success, and confidence}

Table 2 shows the mean values for, and associations amongst, participants' ratings of global importance, confidence, and perceived success for weight loss and weight loss maintenance, BMI, number of previous weight loss attempts, and number of self-reported health conditions. Overall, participants considered that weight loss and weight loss maintenance were extremely important. They perceived themselves to have been slightly successful at weight loss in the past, but unsuccessful at previous weight loss maintenance. Their confidence to lose 
Table 2 Importance, success, and confidence ratings, and correlations with BMI, weight loss attempts, and number of health conditions

\begin{tabular}{|c|c|c|c|c|}
\hline & \multirow[b]{2}{*}{$\begin{array}{l}\text { Mean } \\
\text { (SD) }\end{array}$} & \multicolumn{3}{|c|}{ Correlations [99\% confidence intervals] } \\
\hline & & Current BMI & $\begin{array}{l}\text { No. WL } \\
\text { attempts }\end{array}$ & $\begin{array}{l}\text { No. health } \\
\text { conditions }\end{array}$ \\
\hline $\begin{array}{l}\text { Importance: } \\
\text { WL }\end{array}$ & $\begin{array}{l}5.09 \\
(1.14)\end{array}$ & $\begin{array}{l}0.19[0.12 \text { to } \\
0.26]\end{array}$ & $\begin{array}{l}0.12[0.05 \text { to } \\
0.19]\end{array}$ & $\begin{array}{l}.06[-0.01 \text { to } \\
0.13]\end{array}$ \\
\hline $\begin{array}{l}\text { Importance: } \\
\text { WLM }\end{array}$ & $\begin{array}{l}5.15 \\
(1.11)\end{array}$ & 11 to & & $\begin{array}{l}.07[0.0 \text { to } \\
0.14]\end{array}$ \\
\hline $\begin{array}{l}\text { Success: } \\
\text { WL }\end{array}$ & $\begin{array}{l}3.63 \\
(1.40)\end{array}$ & $\begin{array}{l}-0.07[-0.14 \text { to } \\
0.0]\end{array}$ & $\begin{array}{l}0.01[-0.08 \text { to } \\
0.06]\end{array}$ & $\begin{array}{l}-.08[-0.15 \text { to } \\
-0.01]\end{array}$ \\
\hline $\begin{array}{l}\text { Success: } \\
\text { WLM }\end{array}$ & $\begin{array}{l}2.43 \\
(1.30)\end{array}$ & $\begin{array}{l}-0.23[-0.3 \text { to } \\
-0.16]\end{array}$ & $\begin{array}{l}-0.15[-0.22 \text { to } \\
-0.08]\end{array}$ & $\begin{array}{l}-.06[-0.13 \\
0.01]\end{array}$ \\
\hline $\begin{array}{l}\text { Confidence: } \\
\text { WL }\end{array}$ & $\begin{array}{l}3.34 \\
(1.43)\end{array}$ & $\begin{array}{l}-0.15[-0.22 \text { to } \\
-0.08]\end{array}$ & $\begin{array}{l}-0.05[-0.12 \text { to } \\
0.02]\end{array}$ & $\begin{array}{l}-.15[-0.22 \text { to } \\
-0.08]\end{array}$ \\
\hline $\begin{array}{l}\text { Confidence: } \\
\text { WLM }\end{array}$ & $\begin{array}{l}2.82 \\
(1.36)\end{array}$ & $\begin{array}{l}-0.23[-0.3 \text { to } \\
-0.16]\end{array}$ & $\begin{array}{l}-0.14[-0.21 \text { to } \\
-0.07]\end{array}$ & $\begin{array}{l}-.07[-0.14 \mathrm{t} \\
0.0]\end{array}$ \\
\hline
\end{tabular}

Note. $99 \%$ confidence intervals. All scales from 1 to 6 . All correlations Pearson's r. WL weight loss, WLM weight loss maintenance

weight was slightly low, but their confidence to keep weight off after losing it was significantly lower $\left(t_{(1183)}=\right.$ 15.33, $p<0.001)$.

Participants with higher BMIs considered that weight loss and weight loss maintenance were more important than participants with lower BMIs did. However, participants with higher BMIs were also less confident in their ability to lose weight and to keep it off. BMI was not related to perceptions of past weight loss success, but higher BMI was linked to lower perceived weight loss maintenance success. Participants with higher numbers of previous lifetime weight loss attempts considered weight loss and weight loss maintenance to be more important than those with fewer weight loss attempts. In contrast, perceptions of success and confidence were negatively related to these same factors, such that participants with more numerous lifetime previous weight loss attempts felt less successful and confident at keeping weight off. Participants with greater numbers of health conditions felt less confident at losing weight.

\section{Motivating factors for weight loss}

Participants were asked whether specific motivating factors prompted their decision to lose weight in their current or most recent attempt. Most participants reported that a wish to improve their overall health was a motivating factor $(77 \%)$, followed by unhappiness with body shape/size (64\%), unhappiness with appearance (61\%), wishing to reduce health risks (60\%), wishing to improve physical fitness (55\%), and unhappiness with clothes fitting poorly (52\%). Advice from a primary care professional (GP/nurse) was reported as a motivating factor by $30 \%$ of participants. Other motivating factors included being inspired by others who had recently lost weight (17\%), wanting to lose weight for an upcoming event (16\%), losing weight in response to comments from other people (14\%), and advice from a non-primary care health professional (7\%).

Participants who were motivated by primary care advice to lose weight tended to be older and have a greater number of health conditions $(r=0.12$ and $r=0.13$ respectively, both $p<0.001)$, but they did not tend to have a higher BMI $(r=0.08, p=0.005)$. Instead, participants with a higher BMI were more likely to identify a health scare as a motivating factor $(r=0.12, p<0.001)$. Younger participants and those with a higher BMI were more likely to be motivated by unhappiness with appearance $(r=0.11$ and $r=-0.27$ respectively, both $p<0.001)$. Younger participants were also more likely to be motivated by unhappiness with body size/shape $(r=-0.22, p$ $<0.001)$, wishing lose weight for a special event $(r=$ $-0.20, p<0.001)$, poor fit of clothing $(r=-0.14, p<$ $0.001)$ and wishing to improve fitness $(r=-0.11, p<$ 0.001). Participants with higher numbers of previous weight loss attempts were more likely to cite unhappiness with appearance as a motivating factor $(r=-0.12, p$ $<0.001)$ but were no more likely to endorse any of the other motivating factors.

\section{Weight loss strategies and self-weighing}

Participants were asked whether they had used specific weight loss strategies in the previous 12 months. Figure 1 shows the proportion of participants who reported using each strategy. Self-directed lifestyle modifications were most commonly used, including increasing fruit and vegetable and water consumption (75\% and 58\% respectively), switching to lower calorie food/drink items (57\%), reducing intake of unhealthy foods and drinks (junk food: 63\%; sugary drinks: 54\%; alcohol: 47\%), reducing portion sizes (65\%), and changing eating patterns (e.g., timing of meals: 39\%). Physical activity was used by a smaller proportion of patients: $37 \%$ became more active, $27 \%$ reduced sedentary time, and $26 \%$ took up a sport. Participants used strategies involving professional support less frequently: these included membership of a commercial or local authority weight-loss programme (25\%), using prescription weight loss pills (i.e., Orlistat: $4 \%)$ or using resources from primary care (12\%). Bariatric surgery was used by only $2 \%$. A minority of participants used self-regulatory strategies, which included behavioural self-monitoring using a food diary or phone app (e.g., My Fitness Pal: 11\%) and setting goals (23\%). Participants who used each of these strategies were significantly younger than those who had not used them (all $p$ values $<0.001$ ). Most participants weighed themselves at least weekly (weekly: $30 \%$; several times per week: $8 \%$; daily: $11 \%)$. The others weighed themselves every couple of weeks (12\%), once a month (20\%), or 


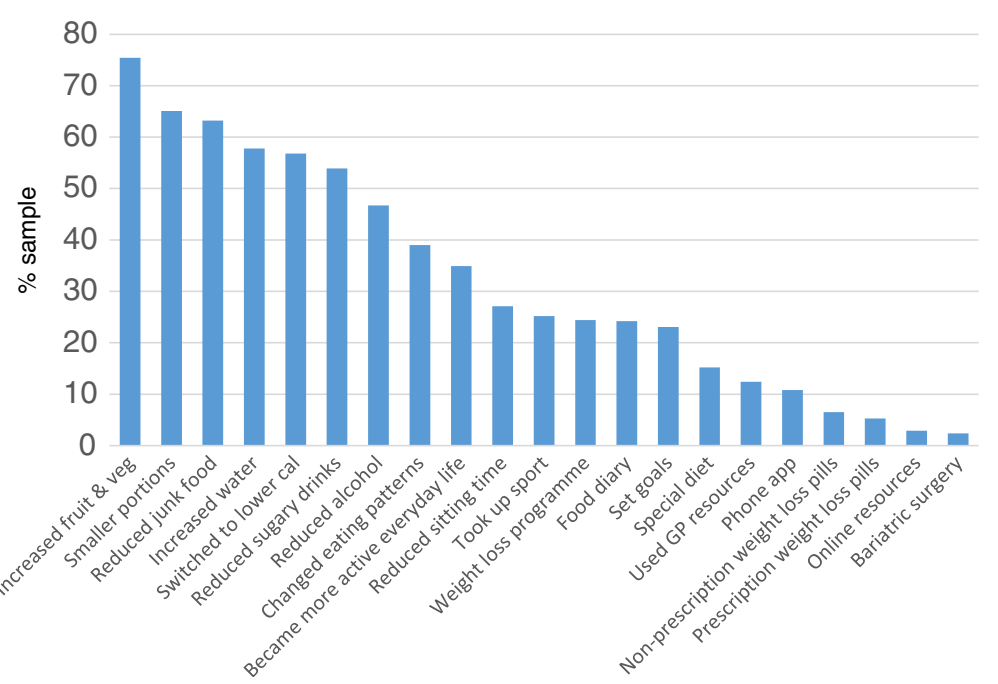

Fig. 1 Proportion of participants who used specific weight loss strategies ( $N=1309)$

never (11\%). The majority of respondents weighed themselves at home $(73 \%)$ rather than in another setting.

\section{Professional weight loss support}

A minority (40\%) of the whole sample had sought some form of professional support in relation to their weight in the past 12 months: from a GP or practice nurse (20\%), commercial weight loss consultant (13\%), dietitian (9\%) or exercise specialist (7\%). Nutritionists, psychologists, and secondary care staff were rarely used for weight loss support (all $<2 \%$ ). Recent use of professional support was significantly higher amongst participants currently trying to lose weight $(49 \%)$ than participants not currently trying $\left(24 \% ; \chi_{(2)}^{2}=54.7, p<0.001\right)$. Of the subgroup of participants trying to lose weight $(n=810), 25 \%$ had consulted a GP or practice nurse: these individuals were highly likely to use GP resources in their weight loss attempt $(r=0.47, p<$ $0.001)$ and likely to report that GP or practice nurse advice motivated their weight loss attempt $(r=0.17, p<0.001)$.

\section{Physical activity}

Levels of physical activity that met current recommendations of at least $75 \mathrm{~min}$ of vigorous activity per week or 150 min of moderate activity per week were reported by $42 \%$ of participants. A greater proportion of men $(49 \%)$ than women $\left(37 \% ; \quad \chi_{(2)}^{2}=18.1, \quad p<0.001\right)$ did so. Participants with recommended levels of physical activity had a slightly lower BMI than those who did not, but this did not reach the threshold for statistical significance $(r=0.08 p<0.01)$. The majority $(60 \%)$ of participants reported no vigorous physical activity at all, whilst $55 \%$ reported no moderate-intensity physical activity, and $15 \%$ reported doing no walking each week. The mean reported time spent walking per day was $15 \mathrm{~min}$ $($ median $=1 \mathrm{~h})$.

\section{Barriers to weight loss}

Participants were asked whether they experienced specific barriers to weight loss during their most recent attempt. Commonly reported barriers included feeling tired $(49 \%)$, stressed $(41 \%)$, demotivated $(38 \%)$ or low (37\%). Participants reported feeling that they were missing out (30\%), getting bored of routine $(28 \%)$, did not have enough time (25\%), and had competing priorities (17\%). Thirty-seven percent of participants also reported that health conditions made it harder to lose weight: conditions perceived as barriers included arthritis $(6 \%$ of total sample), diabetes (5\%), joint/spinal problems (5\%), thyroid problems $(3 \%)$, cardiac problems $(2 \%)$, and respiratory conditions (2\%). Participants with greater numbers of barriers to weight loss had higher BMIs $(r=0.22$, $p<0.001)$ and reported higher numbers of health conditions $(r=0.16, p<0.001)$. They felt less confident about losing weight $(r=-0.15, p<0.001)$ and maintaining weight loss $(r=-0.23, \quad p<0.001)$, and considered themselves less successful at weight loss maintenance $(r=-0.17, p<0.001)$.

\section{Free-text comments about weight control}

At the end of the survey, participants were invited to provide any additional comments in a free-text box. Comments were provided by 498 (38\%) participants. Using a content analytic approach, we double-coded participant comments for common themes. Most provided further details of barriers to weight loss, including physical health $(n=87)$, pain $(n=19)$, limited mobility $(n=$ $19)$, occupational demands $(n=42)$, family commitments $(n=29)$, poor psychological health $(n=52)$, and medication causing weight gain $(n=11)$. Participants stated that insufficient help was available to help them lose weight $(n=23)$, and highlighted the particular difficulty of 
maintaining weight loss once it had been achieved $(n=$ 27). A smaller number described successful weight loss, all with commercial providers $(n=15)$. Others reflected on experiences in primary care that influenced their efforts to lose weight loss $(n=20)$ : most participants described their experiences negatively, highlighting an absence of encouragement or advice.

\section{Discussion}

The results of this cross-sectional survey showed that primary care patients with objectively-recorded obesity were actively engaged in weight loss attempts, considered weight control to be important and had extensive previous experience of trying to lose weight and keep it off. However, participants' confidence and perceived success were low for weight loss and still lower for weight loss maintenance. Weight loss attempts tended to be self-guided (unsupported), using strategies without clear evidence of effectiveness, and were impeded by both psychological and physical health-related barriers. Overall, responses suggested an unmet need for informational support (particularly for weight loss maintenance), sign-posting to structured services, and recognition of the complex experiential and motivational context in which patients attempt weight control.

The majority of survey participants were actively trying to lose weight, indicating that guidance on how to lose weight is likely to be more useful to patients than advice to simply initiate weight loss. It appears more fruitful to capitalise upon and shape patients' existing efforts than to assume that they are currently disengaged. The proportion actively trying to lose weight $(62 \%)$ resembled previous studies with participants with overweight and obesity [21-24] but was lower than in HSE participants with obesity (76\%; [12]). Amongst those trying to lose weight, a minority had recently sought professional weight loss support and only a quarter had sought advice from primary care in the past 12 months, despite health concerns being the most common motivating factor for weight loss, in keeping with previous research $[24,25]$. Those that did seek primary care advice were highly likely to go on to use primary care resources for weight loss and cite the advice received as a motivating factor in their weight loss attempt. Overall, this indicates that primary care advice and signposting has the potential to augment the activities of primary care patients not already using it, and complements existing evidence that such support is acceptable to, and would be viewed favourably by, patients [26, 27].

The most commonly-used weight loss strategies were those with inconclusive evidence for weight loss effectiveness, so providing information about the bestevidenced strategies may be useful to many primary care patients with obesity. Popular strategies were coherent with self-guided 'healthy lifestyle' advice but have not been shown to be effective weight loss interventions in isolation: these included increasing fruit and vegetable consumption [28, 29], reducing portion size [30] and drinking more water [31]. Strategies with stronger evidence bases, such as following a structured weight loss programme [32], using Orlistat [33], and goal setting and self-monitoring [34, 35] were used less frequently. Indeed, the finding that most participants' weight loss strategies were essentially self-guided (unsupported) is of particular concern given participants' limited confidence for weight loss and weight loss maintenance. Although we did not ask about participants' weight loss maintenance strategies, it is notable that overall confidence for maintenance was lower than that for weight loss, suggesting a greater need for support in this area. Overall, information that explicitly differentiates 'health' from 'weight loss' messages may be of particular benefit, as may recommendations for existing, supported weight loss programmes or drug regimens [32, 33].

Participants were less confident about maintaining weight loss than losing weight, and felt less successful at maintenance than loss, indicating the need for maintenance-specific advice and support. Whilst effective weight loss maintenance interventions exist [36], scalable interventions do not yet [37], and thus maintenance provision is limited in both commercial and local authority contexts. UK clinical guidelines contain minimal maintenance-specific content [5-7]. Maintenance confidence and success were lowest amongst those with higher BMIs and more previous weight loss attempts, possibly because repeated attempts and increasing weight ultimately reduced participants' belief that they are capable of keeping weight off over the longer term [38]. Similar relationships were not seen with confidence and success for weight loss. Overall, these findings highlight the importance of sign-posting patients to support, even if they have already achieved some weight loss independently, and of prompting patients to plan ahead for maintenance in discussions of weight loss strategies.

Participants at greatest apparent clinical risk, i.e., those with the highest BMIs and most numerous health conditions, were also those with the lowest confidence for weight loss and weight loss maintenance, indicating that this group of individuals may be in particular need of support. All the aforementioned factors have been shown to be prognostic of poor weight loss and weight loss maintenance in previous research [39, 40]. This group of participants also reported more numerous previous weight loss attempts and barriers, and lower perceived weight loss maintenance success. Health conditions were a key barrier to weight loss for participants, particularly those who were older, had higher BMIs, and lower weight loss confidence. However, this 
group still considered weight loss and weight loss maintenance to be important and were more likely to seek primary care support than others. These findings underscore the need to proactively discuss weight loss with patients with high BMI and multimorbidity, even though primary care staff may avoid doing so when they perceive there are other priorities such as health conditions [41].

Concerns about bodily appearance, size, and shape were particularly pertinent motivating factors to younger patients, as was the wish to become fitter, whereas health concerns were reported as motivating factors by patients of all ages. The latter finding is inconsistent with prior research indicating that health-related motivation for weight loss increases with age, particularly in men [42], but it may be attributable to the comparatively higher mean participant age in the current study. The former finding suggests that primary care staff should be particularly sensitive to the importance of body image and drive to improve fitness amongst younger patients. Counter-intuitively, but in keeping with recent metaanalytic findings [24], younger participants had higher numbers of previous weight loss attempts than older participants, potentially a consequence of greater social pressure to lose weight in this group [43]. Such pressure may also explain our finding that those with greater numbers of weight loss attempts were more likely to be motivated by appearance concerns.

A key strength of the study was the recruitment of participants with recently-recorded objective obesity from systematic searches of GP lists. Weight studies reliant upon self-selection tend to disproportionately attract women [44], whereas men and women were more equally represented in the current sample. Surveys using self-reported BMI data as a determinant of eligibility are vulnerable to the effects of systematic underreporting of weight and over-reporting of height [45]. Here, eligibility was determined using objective data from practice records. The aforementioned underreporting of current weight and height may explain the finding that, according to the self-report survey data, only $83 \%$ of the sample was classified as obese, with $17 \%$ reporting a BMI in the overweight range, and $0.5 \%$ in the healthy weight range. Alternatively, inaccuracies in patient records may explain this, as found in a previous study [46]; a consequent study limitation is that patients with a BMI in the eligible range may have been missed because their weight status has not been correctly coded. The response rate achieved (23\%) is comparable to that of similar ad hoc surveys asking about health and lifestyle behaviours [47-49], but lower than other, larger surveys such as the GP Patient Survey [50]. More than 90\% of participants in the current study self-identified as white. This limits the extent to which the study findings are generalizable to more diverse populations, although it accurately reflects the ethnic composition of the geographical area in which the survey was distributed [51]. The data presented are cross-sectional and, as such, causal inferences are precluded. Finally, data were not available regarding individual participants' frequency of primary care usage, and the sample's demographic composition (e.g., approximately equal numbers of men and women) differs from the typical composition of patients utilising UK primary care consultations [52] although the mean participant age is broadly consistent with it.

\section{Conclusion}

We examined the weight loss support needs of GP patients with objectively-recorded obesity in North East England, and identified the need for informational, structural, and weight loss maintenance-specific support. Study participants were motivated to lose weight and keep it off, but lacked the confidence and understanding of effective strategies required to do this. A minority had sought structured weight management support and fewer still advice from primary care, but those that did found it motivating and useful. GP provision of demonstrably-effective brief referral interventions to structured weight loss support [8] may be acceptable to these patients, to augment their current weight management activities and to optimise limited GP time and resources.

\section{Additional file}

Additional file 1: Study questionnaire. Questionnaire used in study. (PDF $462 \mathrm{~kb}$ )

\section{Abbreviations}

BMI: Body mass index; GP: General practitioner

\section{Acknowledgements}

The authors wish to thank the staff of the North East and Cumbria Clinical Research Network for their invaluable assistance in communicating with practices about the study and coordinating the study distribution process. We are extremely grateful to the partners and other staff of the medical practices involved for agreeing to be involved in the study and for conducting the practice list searches, writing to patients, and labelling questionnaires for distribution. We would like to especially thank the participants who so generously gave their time and effort to completing the weight management survey. We hugely appreciate the contribution of Dr. Stephan Dombrowski (University of Stirling) to the pilot study for this work.

\section{Funding}

The study was partially funded by the UK National Prevention Research Initiative (NPRI) Phase 4 (grant MR/J000477/1). The NPRI includes the following Funding Partners (in alphabetical order): Alzheimer's Research Trust, Alzheimer's Society, Biotechnology and Biological Sciences Research Council, British Heart Foundation, Cancer Research UK, Chief Scientist Office, Scottish Government Health Directorate, Department of Health, Diabetes UK, Economic and Social Research Council, Health and Social Care Research and Development Division of the Public Health Agency (HSC \& R\&D Division), Medical Research Council, The Stroke Association, Wellcome Trust, Welsh Assembly Government and World Cancer Research Fund. FFS is funded by Fuse, the Centre for Translational Research in Public Health, a UKCRC Public Health Research Centre of Excellence based on funding from the British 
Heart Foundation, Cancer Research UK, Economic and Social Research Council, Medical Research Council, and the National Institute for Health Research, under the auspices of the UK Clinical Research Collaboration. The funding body had no role in the study design, data collection, analysis, data interpretation or writing of this manuscript.

\section{Availability of data and materials}

The datasets used and/or analysed during the current study are available from the corresponding author on reasonable request.

\section{Authors' contributions}

FFS and VAS conceived of the study. FFS and EE designed the study and VAS, EE and DK developed questionnaire items. EE and DK implemented the study under the supervision of FFS and VAS. KS, DK and AB transcribed study data and $\mathrm{KS}, \mathrm{EE}$ and $\mathrm{AB}$ carried out data analysis. EE and $\mathrm{KS}$ drafted the manuscript and all authors read and approved the final manuscript.

\section{Ethics approval and consent to participate}

Ethics approval was obtained from the National Research Ethics Service (East Midlands-Derby) on 6th February 2014, REC reference 14/EM/0069. Written consent to participate was obtained via an Informed Consent Form signed and returned by all study participants.

\section{Consent for publication}

Not applicable.

\section{Competing interests}

The authors declare that they have no competing interests.

\section{Publisher's Note}

Springer Nature remains neutral with regard to jurisdictional claims in published maps and institutional affiliations.

\section{Author details}

${ }^{1}$ Institute of Health \& Society, Newcastle University, Newcastle upon Tyne NE2 4AX, UK. ${ }^{2}$ School of Psychology and Speech Pathology, Curtin University, GPO Box U1987, Perth, WA 6845, Australia.

\section{Received: 13 March 2017 Accepted: 20 December 2017}

\section{Published online: 08 January 2018}

\section{References}

1. Ng M, Fleming T, Robinson M, Thomson B, Graetz N, Margono C, Mullany EC, Biryukov S, Abbafati C, Abera SF, et al. Global, regional, and national prevalence of overweight and obesity in children and adults during 19832013: a systematic analysis for the global burden of disease study 2013. Lancet. 2014:384(9945):766-81.

2. Guh DP, Zhang W, Bansback N, Amarsi Z, Birmingham $C L$, Anis AH. The incidence of co-morbidities related to obesity and overweight: a systematic review and meta-analysis. BMC Public Health. 2009;9:88.

3. The Global BMI Mortality Collaboration. Body-mass index and all-cause mortality: individual-participant-data meta-analysis of 239 prospective studies in four continents. Lancet. 2016;388(10046):776-86.

4. Avenell A, Broom J, Brown TJ, Poobalan A, Aucott L, Stearns SC, Smith WCS, Jung RT, Campbell MK, Grant AM. Systematic review of the longterm effects and economic consequences of treatments for obesity and implications for health improvement. Health Technol Assess. 2004;8(21): $1-182$.

5. National Institute of Health and Care Excellence. Obesity: identification, assessment and management of overweight and obesity in children, young people and adults. CG189. London: National Institute of Health and Care Excellence; 2014

6. National Institute of Health and Care Excellence. Obesity in adults: prevention and lifestyle weight management programmes (QS111). London: National Institute of Health and Care Excellence; 2016.

7. Scottish Intercollegiate Guidelines Network. Management of Obesity: a national clinical guideline (115): Scottish Intercollegiate Guidelines Network; 2010.

8. Aveyard P, Lewis A, Tearne S, Hood K, Christian-Brown A, Adab P, Begh R, Jolly K, Daley A, Farley A, et al. Screening and brief intervention for obesity in primary care: a parallel, two-arm, randomised trial. Lancet. 2016; 388(10059):2492-500.

9. Rose SA, Poynter PS, Anderson JW, Noar SM, Conigliaro J. Physician weight loss advice and patient weight loss behavior change: a literature review and meta-analysis of survey data. Int J Obes. 2013;37(1):118-28.

10. Blackburn M, Stathi A, Keogh E, Eccleston C. Raising the topic of weight in general practice: perspectives of GPs and primary care nurses. BMJ Open. 2015;5(8):e008546.

11. Shiffman S, Sweeney CT, Pillitteri JL, Sembower MA, Harkins AM, Wadden TA. Weight management advice: what do doctors recommend to their patients? Prev Med. 2009;49(6):482-6.

12. Piernas $C$, Aveyard $P$, Jebb SA. Recent trends in weight loss attempts: repeated cross-sectional analyses from the Health Survey for England. Int J Obes. 2016:40:1754-9.

13. Jackson SE, Wardle J, Johnson F, Finer N, Beeken RJ. The impact of a health professional recommendation on weight loss attempts in overweight and obese British adults: a cross-sectional analysis. BMJ Open. 2013;3(11): e003693.

14. Bastien M, Poirier P, Lemieux I, Després J-P. Overview of epidemiology and contribution of obesity to cardiovascular disease. Prog Cardiovasc Dis. 2014; 56(4):369-81.

15. Frost GS, Lyons GF. Obesity impacts on general practice appointments. Obes Res. 2005;13(8):1442-9.

16. Puhl R, Peterson JL, Luedicke J. Fighting obesity or obese persons? Public perceptions of obesity-related health messages. Int J Obes. 2013;37(6):77482.

17. Puhl RM, Heuer CA. Obesity stigma: important considerations for public health. Am J Public Health. 2010;100(6):1019-28.

18. Booth ML, Ainsworth BE, Pratt M, Ekelund U, Yngve A, Sallis JF, Oja P. International physical activity questionnaire: 12-country reliability and validity. Med Sci Sport Exerc. 2003;195(9131/03):3508-1381.

19. IBM Corp. IBM SPSS statistics for windows. Version 21.0. Armonk, NY: IBM Corp; 2012.

20. O'Cathain A, Thomas KJ. "Any other comments?" Open questions on questionnaires-a bane or a bonus to research? BMC Med Res Methodol. 2004:4(1):25

21. Johnston DW, Lordan G. Weight perceptions, weight control and income: an analysis using British data. Econ Hum Biol. 2014;12:132-9.

22. Anderson LA, Eyler AA, Galuska DA, Brown DR, Brownson RC. Relationship of satisfaction with body size and trying to lose weight in a national survey of overweight and obese women aged 40 and older, United States. Prev Med. 2002;35(4):390-6.

23. Bish CL, Blanck HM, Maynard LM, Serdula MK, Thompson NJ, Khan LK. Health-related quality of life and weight loss practices among overweight and obese US adults, 2003 Behavioral Risk Factor Surveillance System. MedGenMed. 2007;9(2):35.

24. Santos I, Sniehotta FF, Marques MM, Carraça EV, Teixeira PJ. Prevalence of personal weight control attempts in adults: a systematic review and metaanalysis. Obes Rev. 2016;18(1):32-50.

25. Visram S, Crosland A, Cording H. Triggers for weight gain and loss among participants in a primary care-based intervention. Br J Community Nurs. 2009;14(11):495-501

26. Potter MB, JD V , Croughan-Minihane M. Weight management: what patients want from their primary care physicians. J Fam Pract. 2001;50(6):513.

27. Tan D, Zwar NA, Dennis SM, Vagholkar S. Weight management in general practice: what do patients want? Med J Australia. 2006;185(2):73-5.

28. Mytton OT, Nnoaham K, Eyles H, Scarborough P, Mhurchu CN. Systematic review and meta-analysis of the effect of increased vegetable and fruit consumption on body weight and energy intake. BMC Public Health. 2014; 14(1):1.

29. Kaiser KA, Brown AW, Brown MMB, Shikany JM, Mattes RD, Allison DB. Increased fruit and vegetable intake has no discernible effect on weight loss: a systematic review and meta-analysis. Am J Clin Nutr. 2014:100(2):567-76.

30. Rolls BJ. What is the role of portion control in weight management? Int J Obes. 2014:38(Suppl 1):S1-8.

31. Muckelbauer R, Sarganas G, Grüneis A, Müller-Nordhorn J. Association between water consumption and body weight outcomes: a systematic review. Am J Clin Nutr. 2013; ajcn. 055061

32. Jolly K, Lewis A, Beach J, Denley J, Adab P, Deeks JJ, Daley A, Aveyard P. Comparison of range of commercial or primary care led weight reduction 
programmes with minimal intervention control for weight loss in obesity: lighten up randomised controlled trial. BMJ. 2011;343:d6500.

33. Franz MJ, VanWormer JJ, Crain AL, Boucher JL, Histon T, Caplan W, Bowman JD, Pronk NP. Weight-loss outcomes: a systematic review and meta-analysis of weight-loss clinical trials with a minimum 1-year follow-up. J Am Diet Assoc. 2007;107(10):1755-67.

34. Burke LE, Wang J, Sevick MA. Self-monitoring in weight loss: a systematic review of the literature. J Am Diet Assoc. 2011;111(1):92-102.

35. Greaves CJ, Sheppard KE, Abraham C, Hardeman W, Roden M, Evans PH, Schwarz P. Systematic review of reviews of intervention components associated with increased effectiveness in dietary and physical activity interventions. BMC Public Health. 2011;11(1):1.

36. Dombrowski SU, Knittle K, Avenell A, Araujo-Soares V, Sniehotta FF. Long term maintenance of weight loss with non-surgical interventions in obese adults: systematic review and meta-analyses of randomised controlled trials. BMJ. 2014;348:g2646.

37. Evans EH, Araújo-Soares V, Adamson A, Batterham AM, Brown H, Campbel M, Dombrowski SU, Guest A, Jackson D, Kwasnicka D. The NULevel trial of a scalable, technology-assisted weight loss maintenance intervention for obese adults after clinically significant weight loss: study protocol for a randomised controlled trial. Trials. 2015:16(1):421.

38. Teixeira PJ, Going SB, Sardinha LB, Lohman TG. A review of psychosocial pre-treatment predictors of weight control. Obes Rev. 2005;6(1):43-65.

39. Teixeira PJ, Going SB, Houtkooper LB, Cussler EC, Metcalfe LL, Blew RM, Sardinha LB, Lohman TG. Pretreatment predictors of attrition and successful weight management in women. Int J Obes Relat Metab Disord. 2004;28(9): 1124-33.

40. Elfhag K, Rössner $\mathrm{S}$. Who succeeds in maintaining weight loss? A conceptual review of factors associated with weight loss maintenance and weight regain. Obes Rev. 2005;6(1):67-85.

41. Jochemsen-Van Der Leeuw HGA, Van Dijk N, Wieringa-de Waard M. Attitudes towards obesity treatment in GP training practices: a focus group study. Fam Pract. 2011;28(4):422-9.

42. Hankey C, Leslie WS, Lean MEJ. Why lose weight? Reasons for seeking weight loss by overweight but otherwise healthy men. Int J Obes. 2002;26:880-2.

43. Evans EH, Boothroyd LG, Muscariello E, Stephan BCM, Nasti G, Colantuoni A, Siervo M. Lower weight loss expectations and healthier eating attitudes in older overweight and obese women attempting weight loss. Clin Obes. 2015;5(3):136-44

44. Pagoto SL, Schneider KL, Oleski JL, Luciani JM, Bodenlos JS, Whited MC Male inclusion in randomized controlled trials of lifestyle weight loss interventions. Obesity. 2012;20(6):1234-9.

45. Shiely F, Perry IJ, Lutomski J, Harrington J, Kelleher CC, McGee H, Hayes K. Temporal trends in misclassification patterns of measured and self-report based body mass index categories-findings from three population surveys in Ireland. BMC Public Health. 2010;10(1):1.

46. Sniehotta FF, Dombrowski SU, Avenell A, Johnston M, McDonald S, Murchie $P$, Ramsay CR, Robertson K, Araujo-Soares V. Randomised controlled feasibility trial of an evidence-informed Behavioural intervention for obese adults with additional risk factors. PLoS One. 2011;6(8):e23040.

47. Sahlqvist S, Song Y, Bull F, Adams E, Preston J, Ogilvie D. Effect of questionnaire length, personalisation and reminder type on response rate to a complex postal survey: randomised controlled trial. BMC Med Res Methodol 2011, 11(1):1.

48. Coombes $\mathrm{E}$, Jones AP, Hillsdon $\mathrm{M}$. The relationship of physical activity and overweight to objectively measured green space accessibility and use. Soc Sci Med. 2010;70(6):816-22.

49. Sharpe RA, Thornton CR, Nikolaou V, Osborne NJ. Higher energy efficient homes are associated with increased risk of doctor diagnosed asthma in a UK subpopulation. Environ Int. 2015;75:234-44.

50. Warren FC, Abel G, Lyratzopoulos G, Elliott MN, Richards S, Barry HE, Roland M, Campbell JL. Characteristics of service users and provider organisations associated with experience of out of hours general practitioner care in England: population based cross sectional postal questionnaire survey. BMJ. 2015;350:h2040.

51. Office for National Statistics. Ethnicity and national identity in England and Wales: 2011. London, UK: Office for National Statistics; 2012

52. Hobbs FDR, Bankhead C, Mukhtar T, Stevens S, Perera-Salazar R, Holt T, Salisbury C. Clinical workload in UK primary care: a retrospective analysis of 100 million consultations in England, 2007-14. Lancet. 2016;387(10035): 2323-30.

\section{Submit your next manuscript to BioMed Central and we will help you at every step:}

- We accept pre-submission inquiries

- Our selector tool helps you to find the most relevant journal

- We provide round the clock customer support

- Convenient online submission

- Thorough peer review

- Inclusion in PubMed and all major indexing services

- Maximum visibility for your research

Submit your manuscript at www.biomedcentral.com/submit
Biomed Central 